\title{
Mapping radiation transfer through sea ice using a remotely operated vehicle (ROV)
}

\author{
M. Nicolaus and C. Katlein \\ Alfred-Wegener-Institut, Helmholtz-Zentrum für Polar- und Meeresforschung, Bremerhaven, Germany \\ Correspondence to: M. Nicolaus (marcel.nicolaus@awi.de)
}

Received: 8 August 2012 - Published in The Cryosphere Discuss.: 3 September 2012

Revised: 27 March 2013 - Accepted: 2 April 2013 - Published: 2 May 2013

\begin{abstract}
Transmission of sunlight into and through sea ice is of critical importance for sea-ice associated organisms and photosynthesis because light is their primary energy source. The amount of visible light transferred through sea ice contributes to the energy budget of the sea ice and the uppermost ocean. However, our current knowledge on the amount and distribution of light under sea ice is still restricted to a few local observations, and our understanding of light-driven processes and interdisciplinary interactions is still sparse. The main reasons are that the under-ice environment is difficult to access and that measurements require large logistical and instrumental efforts. Hence, it has not been possible to map light conditions under sea ice over larger areas and to quantify spatial variability on different scales. Here we present a detailed methodological description for operating spectral radiometers on a remotely operated vehicle (ROV) under sea ice. Recent advances in ROV and radiation-sensor technology have allowed us to map under-ice spectral radiance and irradiance on floe scales within a few hours of station time. The ROV was operated directly from the sea ice, allowing for direct relations of optical properties to other sea-ice and surface features. The ROV was flown close to the sea ice in order to capture small-scale variability. Results from the presented data set and similar future studies will allow for better quantification of light conditions under sea ice. The presented experiences will support further developments in order to gather large data sets of under-ice radiation for different ice conditions and during different seasons.
\end{abstract}

\section{Introduction}

The amount of solar short-wave radiation reflected to the atmosphere, absorbed by snow and sea ice, and transmitted into the upper ocean is of critical importance for the surface energy budget of sea-ice covered seas. Together with longwave radiation, turbulent and oceanic heat fluxes, short-wave fluxes determine the formation and melt of sea ice, as well as snow metamorphism and melt. Almost exclusively the visible part of the solar short-wave radiation (visible light) is of critical importance for biological processes (e.g. primary productivity) and biogeochemical fluxes (Arrigo et al., 2012; Deal et al., 2011; Popova et al., 2012). Perovich (2005) demonstrated the importance of light transmitting sea ice by estimating that light penetration through bare and ponded sea ice amount to 16 and $23 \%$ of surface irradiance, respectively. But despite these considerable fractions and the critical biological importance, energy fluxes through snow and sea ice are still not well quantified, and only few systematic and comprehensive studies have been performed.

From various observations, it is known that physical properties and thickness of snow and sea ice are highly variable (e.g. Sturm and Massom, 2009; Warren et al., 1999). This holds for temporal variability from diurnal to seasonal cycles as well as for spatial variability on scales from meters to hundreds of kilometers. As a consequence of this high variability, light transmittance through snow and sea ice is also expected to be very variable (e.g. Grenfell et al., 2006; Light et al., 2008; Mundy et al., 2005; Perovich, 1990), resulting in large differences in the horizontal and vertical distribution of sun light in sea ice and the uppermost ocean.

In addition to changes in the total amount of transmitted solar irradiance, the spectral composition also varies as a 
function of snow, sea-ice, and water properties (Light et al., 2008; Perovich, 1996), as well as through the abundance of biota and sediments (Ficek et al., 2004; Mundy et al., 2007). All these components have specific absorption spectra, impacting spectral radiation in and under sea ice. Based on this, Perovich et al. (1993) and later, in more detail, Mundy et al. (2007) derived methods to estimate under-ice biomass based on optical measurements.

During the last years, the number of studies of spectral light measurements under sea ice has increased. Nicolaus et al. (2010a) presented a comprehensive study of seasonal variability of light transmittance through sea ice, using a stationary setup on drifting multi-year ice in the Arctic (Nicolaus et al., 2010b). Spatial variability was studied in two recent studies. Ehn et al. (2011) quantified the horizontal spreading of light in ponded sea ice, and Frey et al. (2011) described the vertical distribution of light under pond-covered sea ice. However, observations that provide insights into spatial variability over larger distances and that allow repeated transects under different ice conditions or during different seasons are still sparse, and little is known about how light conditions change at different scales. Perovich et al. (1998) performed the first remotely operated vehicle (ROV) based measurements of under-ice irradiance on land-fast sea ice off the coast of Barrow, Alaska, in April 1996. Recently, Nicolaus et al. (2012b) investigated the spatial variability of optical properties of land-fast sea ice in a very similar way, but including repetitions of the transect throughout the melt season. Both studies give insight into the large variability of light transmission of more than one order of magnitude on very short distances. This variability is to be expected during all seasons with sufficient daylight.

A major aspect for the above described advances in spectral radiation measurements under sea ice was the development of different submersible spectral radiometers that are suitable for autonomous measurements, measurements by divers, or mounting sensors on or under ice sleds and remotely operated vehicles. The second necessary aspect to increase measurement progress and efficiency for under-ice studies were advances in ROV technology. It is necessary that the ROV can be operated on and through sea ice (weight, dimensions, vehicle handling), that it can be sufficiently well operated and navigated (vehicle control), and that it is able to carry the required scientific payload (spectral radiometers, additional sensors).

Here we present a technical and methodological manuscript on ROV operations under Arctic sea ice during summer. We made use of advances in instrumentation achieved during the last decade and operated two spectral radiometers on a ROV. This allowed us to measure radiance and irradiance synchronously under different types of drifting Arctic sea ice: ponded and white first-year ice (FYI) and multi year ice (MYI) as well as under new sea ice (frozen lead), and in open water. We show exemplary results from

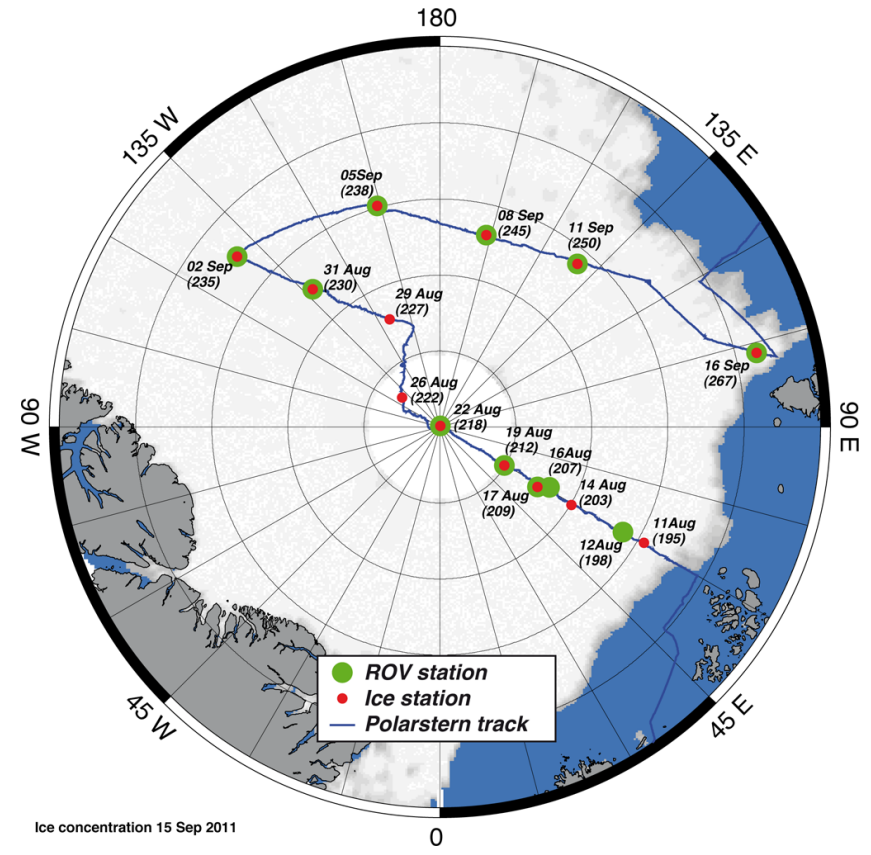

Fig. 1. Ice stations and ROV stations during R/V Polarstern cruise ARK-XXVI/3 (TransArc, 2011). The background image gives seaice concentration on 15 September 2011 (from: http://iup.physik. uni-bremen.de). The magnetic pole was close to the ice station on 31 August 2011.

a comprehensive data set of light conditions under sea ice, which is published in addition to this manuscript.

\section{Methods}

\subsection{Measurements during a trans-polar expedition}

All measurements were performed during the cruise ARK$\mathrm{XXVI} / 3$ (TransArc) of the German icebreaker R/V Polarstern into the Central Arctic Ocean from 4 August to 7 October 2011 (Fig. 1). Successful measurements were performed during 9 ice stations (Fig. 2), covering ponded and white FYI and MYI, new sea ice (frozen lead), and open water. In addition to the optical measurements, a comprehensive data set of sea-ice, surface, and snow properties were recorded in order to classify the optical data and enable developments of parameterizations for radiation fluxes through different ice types. Station duration was mostly about $8 \mathrm{~h}$, except one $36 \mathrm{~h}$ station at the North Pole. Furthermore, stationary optical measurements were performed coincident to sea ice core extractions, but these measurements and data are not included here.

\subsection{ROV instrumentation}

A V8ii ROV (Ocean Modules, Åtvidaberg, Sweden) was used as the sensor platform. This ROV type was selected 

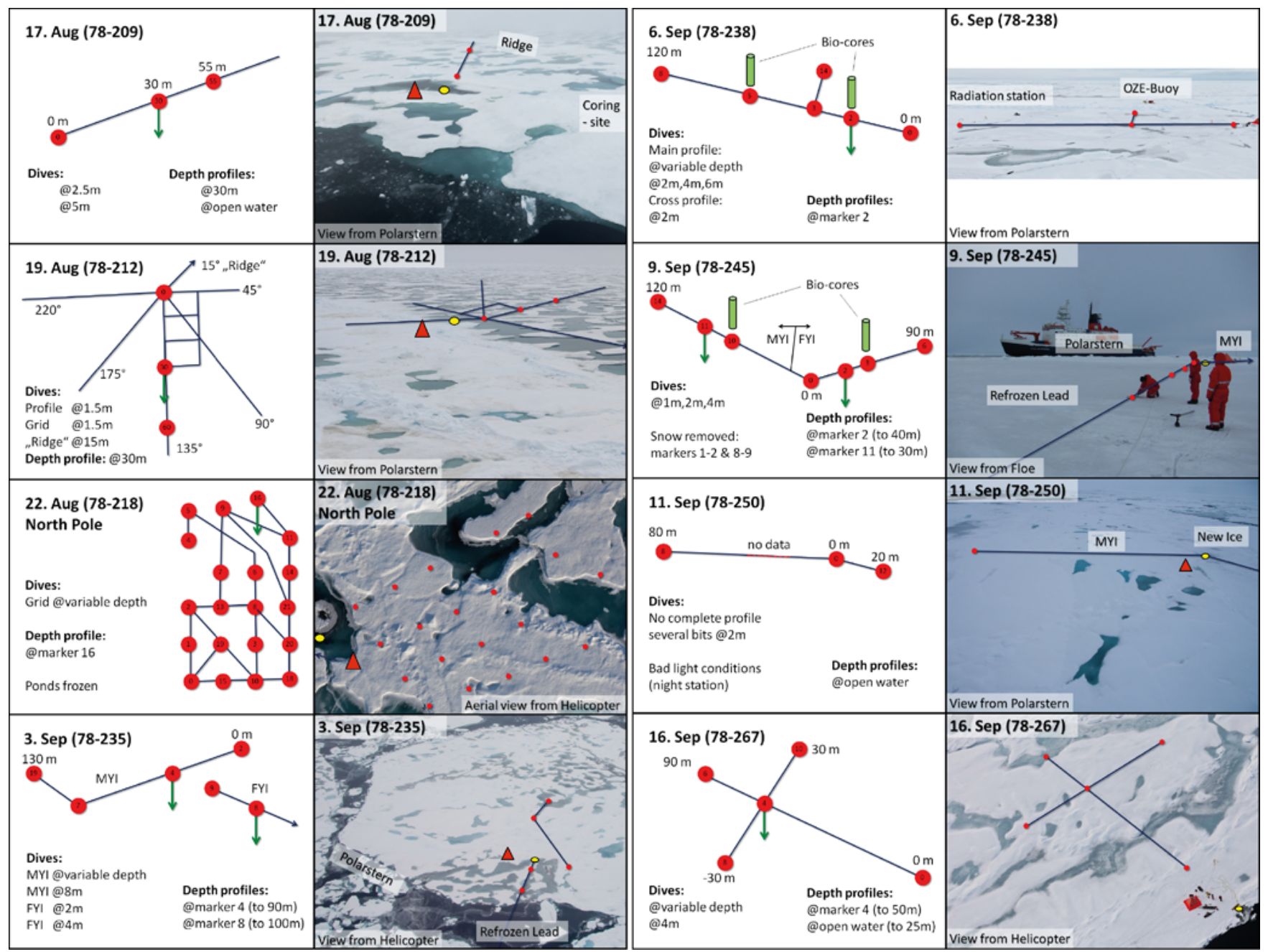

Fig. 2. Sketches and Overview images of ROV sea-ice stations with profile lines (dark blue), selected markers with according numbers (red dots), depth profiles (green arrows), bio-optical cores (light green cylinders), and the depths of main dives. The yellow ellipse indicates the ROV launch hole and the red triangle the location of the pilot tent. The station on 31 August is not listed, because due to technical problems no data were obtained or included into the final data set.

because of its size, power, freedom of movement, and good experiences during an Antarctic expedition (K. Meiners, personal communication, 2011; Antarctic CRC, data unpublished). A main requirement was the possibility to handle it with only two persons on the sea ice and launch and recover it through holes smaller than $1.0 \mathrm{~m}^{2}$. The main instruments on board (payload) were two spectral radiometers (see below, Fig. 3).

The ROV system consisted of a surface unit (incl. power supply, control unit, monitor), a $300 \mathrm{~m}$ long tether cable, and the ROV itself. The ROV is controlled and moved by eight thrusters, allowing a diving speed of up to $1.0 \mathrm{~m} \mathrm{~s}^{-1}$. The standard measurement speed (using $25 \%$ thruster gain) was about $0.25 \mathrm{~m} \mathrm{~s}^{-1}$ for horizontal and vertical profiles. The speed varied from profile to profile and depended on underice currents as well. The ROV was equipped with two VGA video cameras, one zoom-camera looking forward (Typhoon,
Tritech, Aberdeen, UK) and one with a fixed focal length looking backward (Ospray, Tritech, Aberdeen, UK) (Fig. 3). Both cameras were used for navigation (orientation) and to document the dives. The video signal of the forward-looking camera was recorded continuously. An altimeter (DST Micron Echosounder, Tritech, Aberdeen, UK) and a sonar (Micron DST MK2, Tritech, Aberdeen, UK) were mounted to support navigation and measure the distances to obstacles and markers (see below). The altimeter was used to measure the distance between the ROV (finally also the radiometers) and the sea-ice bottom. In addition, the ROV measured its attitude with a suite of internal sensors that are used to stabilize the vehicle during the dives and that are displayed as an overlay together with a time stamp on the control monitor (Fig. 5). A magnetic and a three-axes gyro compass measure heading and are used to calculate turns. Depending on the mode of operation (see below) one or the other is used. Pitch 

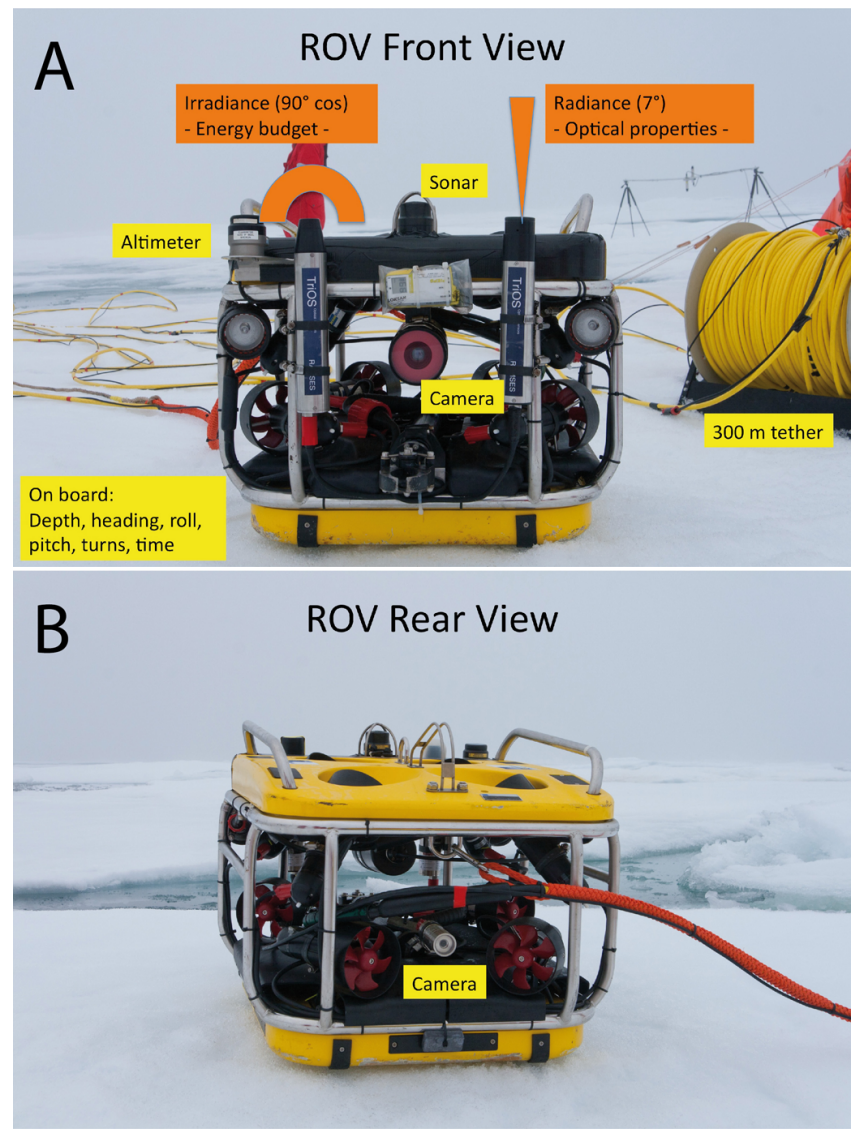

Fig. 3. Annotated photographs of the ROV equipped with sensors for under-ice radiation measurements. (A) Front view including the two Ramses radiometers, one measuring irradiance (left) and one measuring radiance (right). Surface sensors are shown in the back, too. (B) Rear view with tether.

and roll are measured with a three-axes accelerometer, and a pressure sensor is used to derive depth.

\subsection{ROV operation}

The ROV can be powered with a 5-kW generator. But due to a failure of the generator, ship's power had to be used for all measurements. For this, 100 to $150 \mathrm{~m}$ of extension cords had to be laid out from the vessel to the ROV site. This limited the choice of the launch site, but still allowed enough distance to avoid any shadows and obvious influences of the vessel.

In the beginning of the cruise, the ROV was balanced in a pool on the working deck of R/V Polarstern with Arctic seawater. Differently from standard ROV applications, the ROV and the tether were trimmed slightly heavy for the under-ice operations in order to sink in case of failure. Thus it would be hanging straight under the launch hole and could be pulled up again. Salinity variations between the stations, due to sea ice melt, led to slight variations in balancing throughout the cruise, but did not significantly influence the ROV navigation and handling.

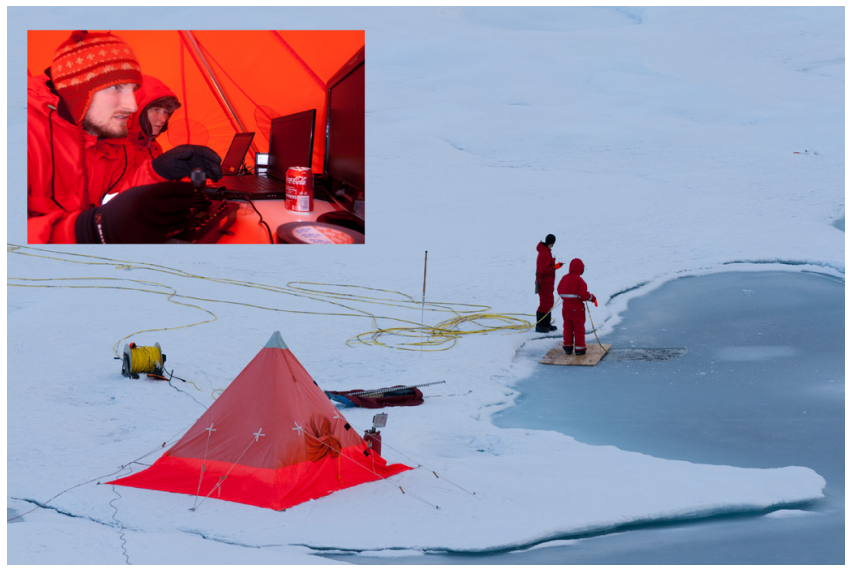

Fig. 4. Photograph of the ROV site taken from onboard R/V Polarstern during the ice station on 2 September 2011. The main picture shows the deployment hole in a frozen melt pond (pond-ice thickness: $5 \mathrm{~cm}$ ), the yellow tether, and the pilot tent. The inset picture shows two ROV pilots, one controlling the ROV and one controlling the sensors and documenting all operations.

All electronics were set up in a pilot tent (Fig. 4), which could be heated when necessary. Flying the ROV was most efficient with four persons: one pilot controlling the ROV, one co-pilot controlling the optical sensors and documenting the dive, one person to handle the tether, and one designated polar-bear guard. In order to reduce the work for access-hole preparation to a minimum, the ROV was mostly launched through melt ponds with only thin ice underneath (Fig. 3). On 16 September, no such pond was present and the ROV was launched over the floe edge at a sheltered location, reducing the risk that drifting ice could block the launch site. After an initial system check and a local test survey to judge the under-ice conditions (visibility, currents, under-ice topography), transects (grids) were marked with numbered, red-white colored poles, hanging under the ice through drill holes (Fig. 5). Marker positions were measured with measuring tape or a handheld GPS receiver and corrected for sea-ice drift after all measurements. The under-ice markers were of critical importance for under-ice orientation, since a designated navigation system was not available for this cruise. For depth profiles (green arrows in Fig. 2), a rope with a weight was lowered through a borehole. Firmly following this rope helped to keep the horizontal position, during descent and ascent, as accurate as possible.

The preferred mode of operation for the ROV is "normal horizon". In this mode, the ROV stabilizes and keeps its position and orientation in the water automatically, except for displacements by currents. This mode was used on the first two ROV stations (until 22 August). Closer to the magnetic pole (approx. at $137.3^{\circ} \mathrm{W}$ and $85.25^{\circ} \mathrm{N}$ ), when the horizontal component of the magnetic field strength was below $2000 \mathrm{nT}$, "normal horizon" could not be used because stabilization requires a stable compass reading. Alternatively, the ROV 

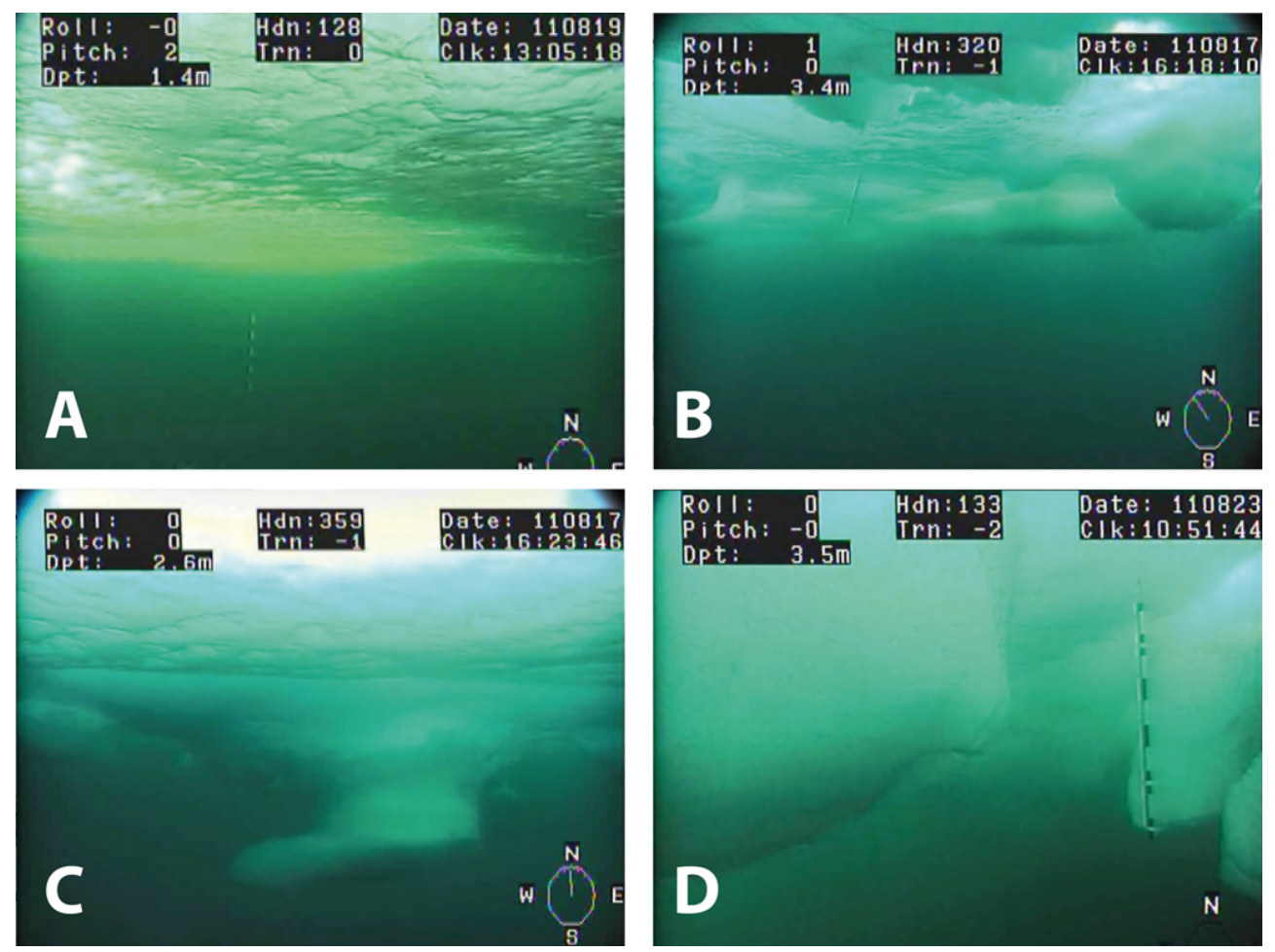

Fig. 5. Impressions of light conditions under sea ice. Photographs are stills of the ROV front camera video. (A) Level ice with a melt pond at the marker position. (B) Patches of level and ridged ice with high variability in light conditions. (C) Ponded ice in front (bright) and ridged ice (darker) in the back. (D) Ridged sea ice. The markers (visible in A and D) are $1.0 \mathrm{~m}$ long. Binary coding of the marker in (D) identifies it as number 19 (IOOII, white marks on the red sections read from bottom up). Overlays give dive information: roll, pitch, depth, heading, turns, date (format: yymmdd), time (UTC), and a compass rosette.

was flown in "deck mode", without any automatic stabilization, but no useful data were recorded since no stable ROV positioning could be achieved (31 August). From 3 September onwards, the magnetic field was again strong enough to prevent the ROV from uncontrolled movements. The ROV was flown in "VG horizon" (a driving mode stabilized by a gyro-compass) or "normal horizon" again. However, due to a strong compass and gyro drift, the heading information could not be used for navigation anymore and more manual adjustments were necessary. Overall, 6 to $8 \mathrm{~h}$ were needed for the presented ROV work during each station. This includes station setup, deployment of under-ice markers, optical and additional measurements, and packing. Longer station times would allow additional dives for more profiles and designated experiments or using additional/alternative payloads.

\subsection{Spectral radiation measurements}

Spectral radiance and irradiance in the wavelength range from 350 to $920 \mathrm{~nm}$ ( $3.3 \mathrm{~nm}$ resolution) were measured with upward-looking Ramses spectral radiometers (Trios GmbH, Rastede, Germany). Technical details about the sensors and data processing are described in Nicolaus et al. (2010b). Under-ice radiance $\left(I_{T}, 7^{\circ}\right.$ field of view) was mainly measured to study the spatial variability of optical properties of sea ice because the measured signal originates from a comparably small area. Under-ice irradiance $\left(E_{T}\right.$, cosine receptor) was mainly measured to study the energy budget at the point of measurement, integrating all incident energy (from above) at this point. The $E_{T}$ sensor (including synchronous pressure and tilt measurements) was directly integrated into the ROV, communicating through the last available twisted pair in the tether. The $I_{T}$ sensor was connected through a separate $150 \mathrm{~m}$ long cable, which was strapped to the tether. This limited the operation radius to $150 \mathrm{~m}$. At the surface, both sensors were connected to a PC running the sensors' software MSDA_xe (TriOS, Rastede, Germany) for triggering and recording. An additional irradiance sensor was mounted on a tripod $1.5 \mathrm{~m}$ above the sea-ice surface close to the profiles (Fig. 3a) to measure incident solar radiation $\left(E_{\mathrm{S}}\right)$. Measurement frequency was set as high as possible for both sensors on the ROV in order to obtain the highest possible spatial resolution. All sensors were triggered synchronously in intervals of 2 to $10 \mathrm{~s}$, depending on light conditions under the ice, resulting in horizontal resolutions between 0.5 and $2.5 \mathrm{~m}$. Integration times of the sensors varied between 512 and $4048 \mathrm{~ms}$. These times depended on ice conditions and were longer for the $E_{T}$ sensor due to the lower light 
transmittance of the opaque cosine receptor. Synchronous $E_{T}$ and $I_{T}$ measurements were done at all stations, except on 22 August when the $E_{T}$ sensor did not work due to a break in the tether cable.

\subsection{Spectral data processing}

All optical data were recorded as raw data and calibrated as described in Nicolaus et al. (2010b) over the full spectral range from 320 to $950 \mathrm{~nm}$. But all data presented and discussed in this manuscript only cover the spectral range of photosynthetically active radiation (PAR) from 400 to $700 \mathrm{~nm}$, because this range is best comparable and most meaningful for all biological applications. All measurements with PAR fluxes below the detection minimum of $0.1 \mathrm{~W} \mathrm{~m}^{-2}$ (corresponding to the maximum of the spectra being lower than $0.4 \mathrm{~mW} \mathrm{~m}^{-2} \mathrm{~nm}^{-1}$ ) were removed from analyses. Here we give all fluxes in $\mathrm{W} \mathrm{m}^{-2}$, while a conversion into $\mu \mathrm{E} \mathrm{m}^{-2} \mathrm{~s}^{-1}$ is possible for the PAR range using $1 \mu \mathrm{E} \mathrm{m}^{-2} \mathrm{~s}^{-1}=0.217 \mathrm{~W} \mathrm{~m}^{-2}$. All spectra were interpolated to a 1-nm grid before calculating ratios from different sensors in order to account for sensor-dependent wavelength grids.

Spectral transmittance $T_{E}(\lambda)$ was calculated as

$T_{E}(\lambda)=E_{T}(\lambda) / E_{S}(\lambda)$

with wavelength $\lambda$. Similar to spectral reflectance (e.g. Perovich, 1996), spectral transflectance

$T_{I}(\lambda)=I_{T}(\lambda) / E_{\mathrm{S}}(\lambda)$

was introduced for radiance fluxes measured under ice or in open water in relation to surface irradiance. Similarly, PAR transmittance

$T_{E, \text { PAR }}=\frac{\int_{400}^{700} E_{T}(\lambda) \mathrm{d} \lambda}{\int_{400}^{700} E_{\mathrm{S}}(\lambda) \mathrm{d} \lambda}$

and PAR transflectance

$T_{I, \text { PAR }}=\frac{\int_{400}^{700} I_{T}(\lambda) \mathrm{d} \lambda}{\int_{700}^{700} E_{\mathrm{S}}(\lambda) \mathrm{d} \lambda}$

were calculated. Both ratios, transmittance and transflectance, are dimensionless quantities. As the SI-system suggests the usage of the unit steradian for solid angles, we add the unit $\mathrm{sr}^{-1}$ to transflectance values.

In order to increase comparability, all measurements were also corrected to the ice/water interface, subtracting the effect of the water between the ice and the sensor. Irradiance depth profiles were measured at representative sites with a homogenous surface each station and analyzed to obtain the extinction characteristics of the local seawater. To calculate the spectral extinction coefficients $k(\lambda)$, the data were fitted for each wavelength or broadband value separately with an exponential decay model

$T_{E}(\lambda, z)=T_{E}\left(\lambda, z_{0}\right) \cdot \exp (-k(\lambda) \cdot z)$ in the upper $8 \mathrm{~m}$ of the water column. The resulting correlation coefficient $R^{2}$ of the fits was better than 0.9 for all extinction spectra. Corrected fluxes at the ice/water interface are then given by

$T_{E_{\text {corrected }}}(\lambda)=\frac{T_{E_{\text {measured }}}(\lambda)}{\exp (-k(\lambda) \cdot d)}$,

where the distance to the ice $d$ is given by the altimeter measurement. During the stations on 22 August and 31 August, no irradiance depth profiles could be recorded and extinction characteristics from 19 August and 2 September were used instead. Although this method of extracting extinction coefficients from depth profiles introduces some uncertainty due to high spatial variability of surface properties and its impact on depth profiles (Frey et al., 2011), we found this to be the only consistent solution. Using literature or other constant values would have introduced larger uncertainties, and it was not possible to measure the extinction coefficient directly along each profile. In addition, the application of exponential fits also represents an improvement compared to the linear approach presented in Nicolaus et al. (2010b).

During and after the cruise, all sensors were set up for comparison measurements in order to obtain uncertainties and relative differences in measured fluxes. These were expected based on earlier experiences for low solar elevation angles due to inaccuracies of the cosine receptor of the irradiance sensors. This intercomparison revealed differences of up to $5 \%$ with reproducible characteristics of single sensors. Hence, these differences were corrected during data processing by wavelength-independent scaling of measured fluxes.

Another error source that had to be accounted for during data processing was a high noise level on some radiance spectra. This resulted most likely from insufficient grounding of the radiance sensor, which was operated through an extra cable. All fluxes at wavelengths $<350$ and $>800 \mathrm{~nm}$ were removed. Afterwards, a spectral value was replaced by a $7-$ point running mean if its value differed from a 3-point running mean by more than $3 \%$. This method was found to be most efficient in terms of data quality and had the smallest influence on the measured signal itself. As a consequence, upcoming applications will only use sensors operated through the ROV without extra cables.

In order to assess uncertainties resulting from tilt angles of the spectral radiometers due to pitch and roll of the ROV, additional Monte Carlo simulations for radiative transfer through sea ice using the model from Petrich et al. (2012) were performed. Neglecting scattered light from the water column, a sensor ( $=$ ROV) tilt by 10 (20) degrees under a homogenous sea-ice cover results in a deviation of $0.3(2.0) \%$ for irradiance and $0.3(6.0) \%$ for radiance measurements. Since these deviations for tilts up to $10^{\circ}$ are much smaller than all the other error sources of this kind of measurements, these deviations are not corrected. Furthermore, introducing a pitch and roll correction for small angles would increase uncertainties, because such a correction would depend on 
other measures and assumptions that have larger uncertainties than the uncorrected spectra, e.g. optical water properties, spreading of light under sea ice, radiometer integration times and the under-ice topography. For inhomogeneous ice conditions, the pitch and roll errors cannot be generally quantified because they highly depend on the ice geometry and the relative tilt to these structures. However, in this case, the tilt error can be considered as an "effective position error" as small as $17 \mathrm{~cm}$ (for $10^{\circ}$ sensor tilt and $1 \mathrm{~m}$ distance to the ice), which again is much smaller than the position error.

\subsection{Additional measurements and under-ice positioning}

In addition to the spectral radiation measurements, seaice conditions along each transect were documented and assigned to each optical measurement (spectrum). Sea-ice thickness, snow depth, surface layer thickness or pond depth, and freeboard were measured at each marker (Fig. 2). Additional measurements of total sea-ice thickness were performed by EM31-measurements along the ROV-transects after completing all dives. Sea ice types, snow cover, and meltponds were documented. Local $x$ and $y$ coordinates were assigned to each under-ice measurement based on pass-times of the markers (from the video recordings). Measurement depth ( $z$ coordinate) was used from the ROV pressure sensor, because this depth was available for all measurements, other than the measurement of the Ramses IP module, which was not available for all $I_{T}$ spectra. The position accuracy is expected to be better than $1.0 \mathrm{~m}$ in all three dimensions. Uncertainties of the horizontal position during depth profiles and deeper horizontal transects are likely larger and also increasing with depth, but unknown. Constant $x-y$ coordinates are assumed for all depth profiles, since no better information about horizontal displacement is available. Finally, 3-D coordinates and all other properties were interpolated and assigned to each spectrum. All measurements that could not be located due to uncertain dive tracks were discarded for further analyses.

\section{Results}

\subsection{Advances in methodology}

Operation of two spectral radiometers on the ROV allowed for the collection of a comprehensive data set of radiation transmission through Arctic sea ice, representing light conditions and optical properties of sea ice and water along several kilometers of profiles under Arctic sea ice. Most obvious is the good measurement progress and the flexibility to perform horizontal and vertical transects under very different ice conditions. The ROV operations allowed efficient and nondestructive mapping of under ice radiation, covering a large degree of spatial variability at different scales. The net dive time of the ROV was below $2 \mathrm{~h}$ on each ice station, while the entire station time was 6 to $8 \mathrm{~h}$, including all sea-ice and snow observations, as well as setup. It would not have been possible to gather a similar data set with measurements through bore holes from the surface or with divers. Accessing the under-ice environment through the ponds on the sea ice was found to be efficient and convenient, since the ponds provided a sheltered spot with thinner (if any) sea ice. Working directly from sea ice, compared to ship-based operation, allows in situ observations of sea-ice properties and types, necessary information to relate measured fluxes and transmittances to sea-ice conditions. It also allows researchers to be more efficient in the use of ship's time, because other measurements, e.g. CTD casts, can be performed in parallel and do not interfere with the ROV work. Balancing the tether and the ROV slightly heavy reduces the risk of tether tangling under the sea ice to a minimum. During the presented work, no such incident was encountered.

The ROV type itself was highly adequate for this kind of measurements. Dimensions and weight were small enough to be handled by two persons, including launch and retrieval without additional tools. The thrusters were strong enough to navigate the ROV in the desired direction, also for seaice drift speed around $0.5 \mathrm{kn}$. The ROV payload was large enough to carry the two additional sensors, and it would have been large enough to add a few more small sensors (e.g. for temperature, salinity, oxygen, fluorescence). However, future campaigns will benefit from using a fiber-optics tether with higher data capacity, as needed for HD video signals and additional sensors.

Another new and beneficial aspect was to operate radiance and irradiance sensors synchronously. With this concept, both spatial variability and energy budgets were quantified along identical transects. Comparing synchronous pairs of $I_{T}$ and $E_{T}$ shows that it is not possible to scale measured radiance with a factor of $\pi(=3.1416)$ to obtain irradiance as described earlier (Frey et al., 2011; Grenfell, 1991; Roulet et al., 1974). Hence, the new term of transflectance is introduced to relate under-ice radiance with surface irradiance (Eq. 2).

Based on the presented methods, measuring light transmission through sea ice became more efficient than before and the resulting data set allows new insights into spatial variability of under-ice radiation. The measurements were performed during 9 successful ice stations along 51 horizontal profiles with a total length of $4.4 \mathrm{~km}$. In addition, 11 depth profiles, reaching depths $>10 \mathrm{~m}$, were recorded. All measurements as well as corresponding surface and ice conditions are summarized in Fig. 2 and Table 1. After processing, the final data set consists of 2900 irradiance and 6400 radiance spectra with a mean horizontal resolution of about 1.0 $\mathrm{m}$. In this respect, it was also found to be beneficial to include a variety of ROV-internal measurements (distance to ice, depth, ROV attitude) in the data set. Together with the surface observations, this multi-sensor approach is likely beneficial to a variety of interdisciplinary applications, and can easily be extended with more sensor types on the ROV. The 
A
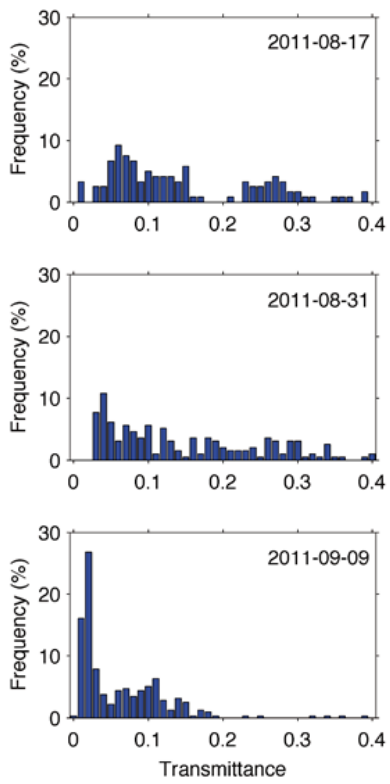

B
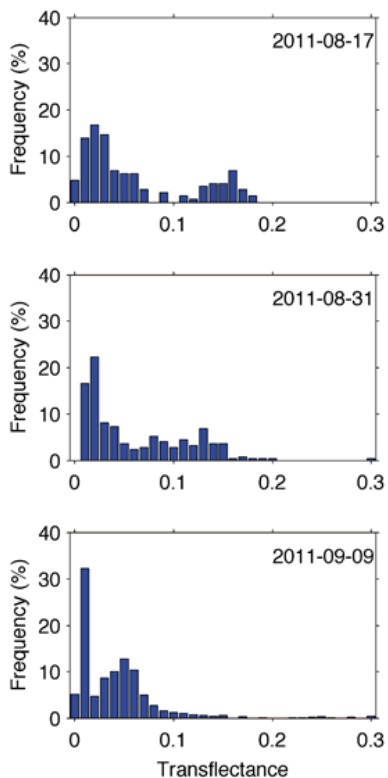
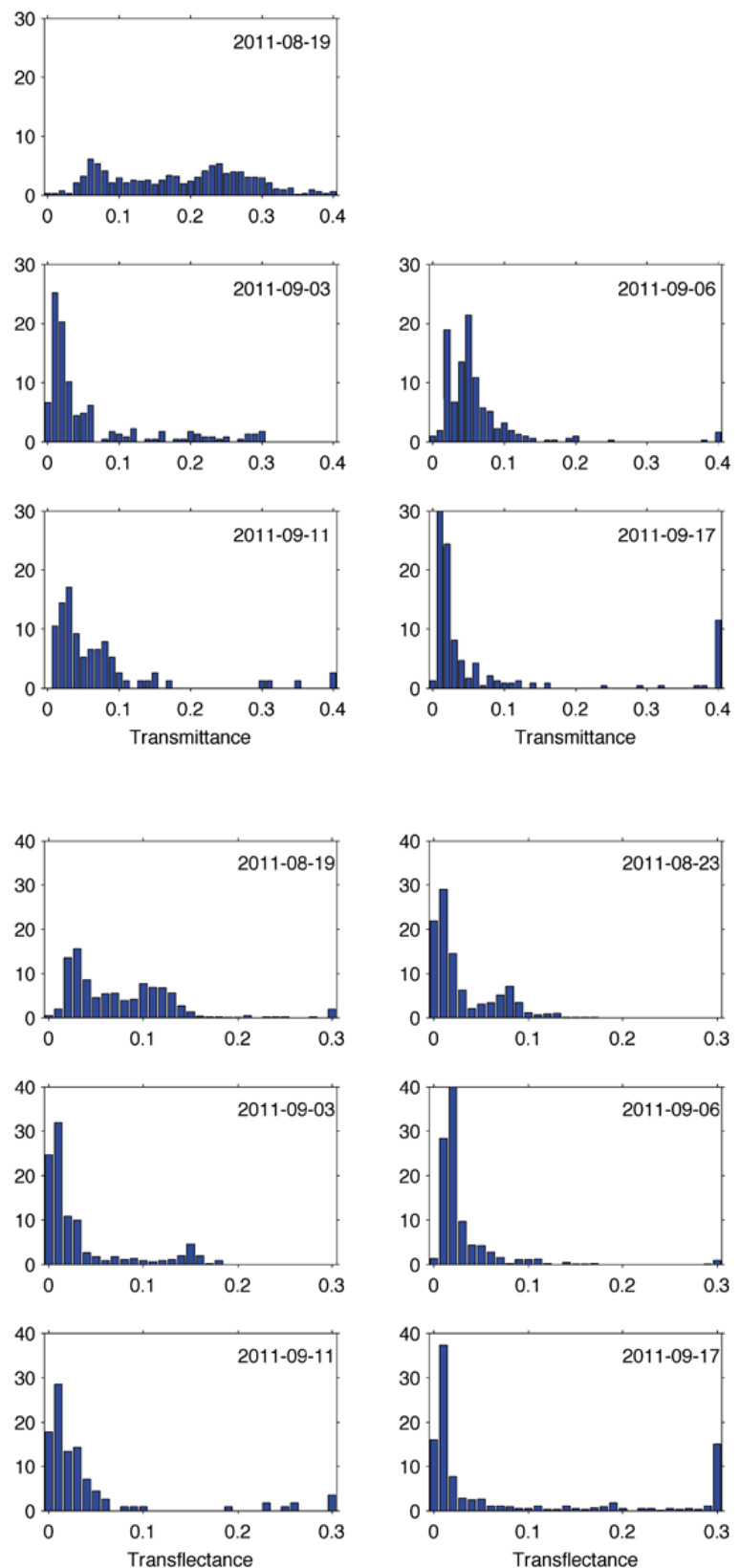

Fig. 6. (A) PAR transmittance and (B) PAR transflectance of all measurements for each station. All bins are 0.01 wide. No transmittance measurements on 23 August. Transflectance is given $\mathrm{sr}^{-1}$.

final data set of all spectra and metadata contains all fields summarized in Table 2. This data set is published and made available online under doi:10.1594/PANGAEA.786717. It is expected to be useful for future applications, e.g. in comparison with other ROV or autonomous under-water vehicle (AUV) transects or for more statistical analyses.

\subsection{Transmission through sea ice}

Figure 6 shows frequency distributions of PAR transmittance and PAR transflectance for each of the 9 ice stations.
Modes of the frequency distributions mostly represent the difference between white ice and melt ponds. Comparing both plots for each station, characteristic differences become obvious. (1) Modes of transflectance are more pronounced than for transmittance, representing the different characteristics of the radiance and the irradiance sensors. (2) White ice modes of transflectance range up to $0.03 \mathrm{sr}^{-1}$ and are lower than those for melt ponds, ranging from 0.08 to $0.16 \mathrm{sr}^{-1}$. Only modes for open water were found to be higher (station on 17 September). (3) The distribution functions of transflectance show that the spatial variability of light 
Table 1. All ROV transects that are included in the final data set. Dates (UTC) refer to the ROV measurements (not necessarily the station beginning). Markers are named with "M" and their number, e.g. M6 for marker number 6. The station number gives the official R/V Polarstern station number as reference for any other observations during the cruise. Abbreviations: MYI - multi-year sea ice, FYI - first-year sea ice. The station on 31 August is not listed, because due to technical problems no data from that date were obtained or included in the final data set.

\begin{tabular}{|c|c|c|c|c|c|}
\hline $\begin{array}{l}\text { Date } \\
\text { Station }\end{array}$ & $\begin{array}{l}\text { Surface conditions } \\
\text { Pond status }\end{array}$ & Profile (@ ROV depth) & $\begin{array}{l}\text { Length/Depth } \\
(\mathrm{m})\end{array}$ & Sea ice and thickness & Comments \\
\hline $\begin{array}{l}17.08 .11 \\
78-209\end{array}$ & $\begin{array}{l}\text { No snow, } \\
\text { open ponds }\end{array}$ & $\begin{array}{l}\text { Profile@ } 2.5 \mathrm{~m} \\
\text { Profile@ } 5.0 \mathrm{~m} \\
\text { Profile @ ice bottom } \\
\text { Profile @ ice bottom } \\
\text { Depth@ M30 } \\
\text { Depth }\end{array}$ & $\begin{array}{l}100 \\
50 \\
30 \\
\text { no data } \\
50 \\
13\end{array}$ & $\begin{array}{l}\text { FYI } 1.1 \mathrm{~m} \\
\text { FYI } 1.1 \mathrm{~m} \\
\text { FYI } 1.1 \mathrm{~m} \\
\text { FYI } 1.1 \mathrm{~m} \\
\text { FYI } 1.1 \mathrm{~m} \\
\text { Open water }\end{array}$ & $\begin{array}{l}\text { "Stop and go" mode } \\
\text { Continuous, bad positioning }\end{array}$ \\
\hline $\begin{array}{l}19.08 .11 \\
78-212\end{array}$ & $\begin{array}{l}\text { No snow, } \\
\text { open ponds }\end{array}$ & 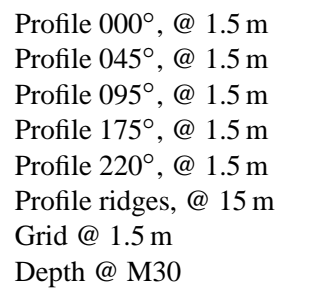 & $\begin{array}{l}120 \\
60 \\
120 \\
120 \\
150 \\
\text { points } \\
30 \times 15 \\
50\end{array}$ & $\begin{array}{l}\text { FYI } 1.2 \mathrm{~m} \\
\text { FYI } 1.2 \mathrm{~m} \\
\text { FYI } 1.2 \mathrm{~m} \\
\text { FYI } 1.2 \mathrm{~m} \\
\text { FYI } 1.2 \mathrm{~m} \\
\text { MYI }<8.0 \mathrm{~m} \\
\text { FYI } 1.2 \mathrm{~m} \\
\text { FYI } 1.2 \mathrm{~m}\end{array}$ & \\
\hline $\begin{array}{l}22.08 .11 \\
78-218\end{array}$ & $\begin{array}{l}\text { Frozen surface } \\
\text { and ponds, no snow }\end{array}$ & $\begin{array}{l}\text { Grid @ variable depth } \\
\text { Depth @ M16 }\end{array}$ & $\begin{array}{l}30 \times 50 \\
10\end{array}$ & $\begin{array}{l}\text { MYI } 1.5-3.5 \mathrm{~m} \\
\text { MYI } 1.5-3.5 \mathrm{~m}\end{array}$ & Only radiance sensor \\
\hline $\begin{array}{l}03.09 .11 \\
78-235\end{array}$ & $\begin{array}{l}2-3 \mathrm{~cm} \text { new snow, } \\
\text { ponds frozen }(10 \mathrm{~cm})\end{array}$ & $\begin{array}{l}\text { Profile } 1 @ 4-8 \mathrm{~m} \\
\text { Profile } 1 @ 8 \mathrm{~m} \\
\text { Profile } 1 @ \text { variable depth } \\
\text { Profile } 2 \text { @ } 2 \mathrm{~m} \\
\text { Depth @ M4 } \\
\text { Depth @ M8 } \\
\text { Surface depth profile }\end{array}$ & $\begin{array}{l}2 \times 130 \\
2 \times 130 \\
120 \\
2 \times 80 \\
90 \\
100 \\
5\end{array}$ & $\begin{array}{l}\text { MYI } 2.0-3.8 \mathrm{~m} \\
\text { MYI } 2.0-3.8 \mathrm{~m} \\
\text { MYI } 2.0-3.8 \mathrm{~m} \\
\text { FYI } 1.2 \mathrm{~m} \\
\text { MYI close FYI } \\
\text { FYI close water } \\
\text { MYI/FYI }\end{array}$ & \\
\hline $\begin{array}{l}06.09 .11 \\
78-238\end{array}$ & $\begin{array}{l}\text { Snow } 3 \mathrm{~cm} \text {, } \\
\text { ponds frozen }\end{array}$ & $\begin{array}{l}\text { Profile @ } 1.2 \mathrm{~m} \\
\text { Profile @ } 2.0 \mathrm{~m} \\
\text { Profile @ } 4.0 \mathrm{~m} \\
\text { Profile @ } 6.0 \mathrm{~m} \\
\text { Profile @ variable depth } \\
\text { Cross profile @ } 3.0 \mathrm{~m} \\
\text { Depth@ M2 } \\
\text { Depth }\end{array}$ & $\begin{array}{l}30 \\
120 \\
120 \\
105 \\
120 \\
70 \\
50 \\
5\end{array}$ & $\begin{array}{l}\text { FYI } 0.8 \mathrm{~m} \\
\text { FYI } 0.8 \text { (to } 2.0 \text { ) } \\
\text { FYI } 0.8 \text { (to 2.0) } \\
\text { FYI } 0.8 \text { (to 2.0) } \\
\text { FYI } 0.8 \text { (to 2.0) } \\
\text { FYI } 0.8 \\
\text { FYI } 0.8 \text { (to 2.0) } \\
\text { FYI } 0.8 \text { (to 2.0) }\end{array}$ & Bad positioning \\
\hline $\begin{array}{l}09.09 .11 \\
78-245\end{array}$ & $\begin{array}{l}\text { Snow } 10 \mathrm{~cm} \text {, } \\
\text { ponds frozen }\end{array}$ & $\begin{array}{l}\text { Profile@1.0m } \\
\text { Profile @ } 1.2 \mathrm{~m} \\
\text { Profile } @ 2.0 \mathrm{~m} \\
\text { Profile @ } 4.0 \mathrm{~m} \\
\text { Profile @ } 1.0 \mathrm{~m} \text { no snow } \\
\text { Profile@ } 2.0 \mathrm{~m} \text { no snow } \\
\text { Profile@ } 2.0 \mathrm{~m} \text { no snow } \\
\text { Depth@ } \text { M2 } \\
\text { Depth@ M11 }\end{array}$ & $\begin{array}{l}120 \\
90 \\
2 \times 210 \\
210 \\
15 \\
15 \\
15 \\
40 \\
25\end{array}$ & $\begin{array}{l}\text { FYI } 1.2 \mathrm{~m} \\
\text { New ice } 0.3 \mathrm{~m} \\
\text { FYI + new ice } \\
\text { FYI + new ice } \\
\text { New ice } 0.3 \mathrm{~m} \\
\text { New ice } 0.3 \mathrm{~m} \\
\text { FYI } 1.2 \mathrm{~m} \\
\text { New ice } 0.3 \mathrm{~m} \\
\text { FYI } 1.2 \mathrm{~m}\end{array}$ & $\begin{array}{l}\text { New ice }=\text { frozen lead } \\
\text { Snow removed M8-M9 } \\
\text { Snow removed M8-M9 } \\
\text { Snow removed M1-M2 }\end{array}$ \\
\hline $\begin{array}{l}11.09 .11 \\
78-250\end{array}$ & $\begin{array}{l}\text { Ponds frozen, snow } \\
\text { covered }\end{array}$ & $\begin{array}{l}\text { Profile @ } 2.0 \mathrm{~m} \\
\text { Depth } \\
\text { Depth }\end{array}$ & $\begin{array}{l}\text { Ca. } 4 \times 30 \\
10 \\
3\end{array}$ & $\begin{array}{l}\text { New ice }+ \text { MYI } \\
\text { Open water } \\
\text { Open water }\end{array}$ & $\begin{array}{l}\text { Bad data quality (night) } \\
\text { Bad data quality (night) } \\
\text { Bad data quality (night) }\end{array}$ \\
\hline $\begin{array}{l}16.09 .11 \\
78-267\end{array}$ & $\begin{array}{l}\text { Ponds frozen, snow } \\
\text { covered }\end{array}$ & $\begin{array}{l}\text { Profile @ } 4.0 \mathrm{~m} \\
\text { Profile @ variable depth } \\
\text { Depth @ M4 } \\
\text { Depth }\end{array}$ & $\begin{array}{l}\text { Total } 450 \\
\text { Total } 240 \\
50 \\
25\end{array}$ & $\begin{array}{l}\text { MYI } 1.7 \text { to } 2.9 \mathrm{~m} \\
\text { MYI } 1.7 \text { to } 2.9 \mathrm{~m} \\
\text { MYI } 1.7 \text { to } 2.9 \mathrm{~m} \\
\text { Open water }\end{array}$ & \\
\hline
\end{tabular}


Table 2. Variables and units of the spectral and meta data set as presented in this manuscript and published online under doi:10.1594/PANGAEA.786717.

\begin{tabular}{|c|c|c|c|}
\hline Variable & Symbol & Unit & Comment \\
\hline \multicolumn{4}{|l|}{ Radiation data } \\
\hline Irradiance, incident (spectral) & $E_{\mathrm{S}}$ & $\mathrm{W} \mathrm{m} \mathrm{m}^{-2} \mathrm{~nm}^{-1}$ & \\
\hline Irradiance, incident (PAR) & $E_{\mathrm{S}, \mathrm{PAR}}$ & $\mathrm{W} \mathrm{m}^{-2}$ & \\
\hline Irradiance, transmitted (spectral) & $E_{T}$ & $\mathrm{~W} \mathrm{~m} \mathrm{~m}^{-2} \mathrm{~nm}^{-1}$ & \\
\hline Irradiance, transmitted (PAR) & $E_{T, \mathrm{PAR}}$ & $\mathrm{W} \mathrm{m}^{-2}$ & \\
\hline Radiance, transmitted (spectral) & $I_{T}$ & $\mathrm{~W} \mathrm{~m}^{-2} \mathrm{~nm}^{-1} \mathrm{sr}^{-1}$ & \\
\hline Radiance, transmitted (PAR) & $I_{T, \mathrm{PAR}}$ & $\mathrm{W} \mathrm{m} \mathrm{m}^{-2} \mathrm{sr}^{-1}$ & \\
\hline Transmittance (spectral) & & & see Eq. (1) \\
\hline Transmittance (PAR) & $T_{E, \mathrm{PAR}}$ & & see Eq. (3) \\
\hline Transflectance (spectral) & $T_{I}$ & $\mathrm{sr}^{-1}$ & see Eq. (2) \\
\hline Transflectance (PAR) & $T_{I, \mathrm{PAR}}$ & $\mathrm{sr}^{-1}$ & see Eq. (4) \\
\hline \multicolumn{4}{|l|}{ Meta data } \\
\hline Date/Time & $t$ & String & \\
\hline$x$ coordinate & $x$ & $\mathrm{~m}$ & \\
\hline$y$ coordinate & $y$ & $\mathrm{~m}$ & \\
\hline$z$ coordinate $=$ depth & $z$ & $\mathrm{~m}$ & \\
\hline Sea-ice thickness & $z_{\mathrm{i}}$ & $\mathrm{m}$ & \\
\hline Snow depth & $z_{\mathrm{s}}$ & $\mathrm{m}$ & \\
\hline Freeboard & $f b$ & $\mathrm{~m}$ & \\
\hline
\end{tabular}

transmission through sea ice ranges over more than one order of magnitude for all stations. Beyond the results from this manuscript, Nicolaus et al. (2012a) show, using the presented data set, that light transmittance through MYI was generally lower than through FYI. This finding was also used for a new parameterization in order to generalize findings from this data set to the entire Arctic during summer.

However, transmission ratios and fluxes strongly varied from station to station, because light transmission does not only depend on ice types (FYI, MYI, new ice), but in particular also on surface conditions (scattering layer, snow cover, wet and frozen surfaces) and ice properties (thickness and texture). Merging all data, the frequency distribution for the entire expedition (not shown here) does not reveal as clear modes (see also Nicolaus et al., 2012a). This is mostly because surface conditions changed during the cruise and an increasing snow cover towards the end of the cruise reduced light transmission, resulting in a shift of the modes towards lower values. Finally, this shows that the spatial heterogeneity is strongly influenced by seasonal (temporal) variability (Nicolaus et al., 2012b).

Exemplary for all the transects, Fig. 7 shows the transflectance and transmittance at the ice/water interface (incl. the above described correction, Eq. 6) from repeated measurements along the same profile at depths of $1.0 \mathrm{~m}, 2.0 \mathrm{~m}$ (twice), and $4.0 \mathrm{~m}$. The profile includes measurements under snow-covered FYI and a refrozen lead (new ice) on 9 September. The aims of these repetitions were (1) to compare two identical flights (same profile, same depth) in order to illustrate differences from different (horizontal) sampling of the same profile, (2) to illustrate the effect of increasing measurement (sensor) depth on the potential to resolve horizontal variability, and (3) compare PAR transmittances as a result of the applied depth corrections. The geometry of snow and sea ice as measured and interpolated from manual drillings is shown in Fig. 7a. Sea-ice thickness ranged from 0.12 to $1.58 \mathrm{~m}$, snow depth from 0.00 to $0.18 \mathrm{~m}$, and freeboard from 0.01 to $0.49 \mathrm{~m}$. Over all thickness measurements, it was found that sea-ice draft readings obtained from drillings and the ROV matched sufficiently well. Hence, the derived draft values may also be used for further studies, e.g. to include sea-ice thickness into light-transmission parameterizations.

The differences in PAR transflectance of the two dives at $2.0 \mathrm{~m}$ depth (Fig. 7b) show the same pattern of higher light transmission through the thinner new ice than the FYI. Total transflectances for snow-covered new ice ( 0.04 to $\left.0.06 \mathrm{sr}^{-1}\right)$ and FYI $\left(<0.01 \mathrm{sr}^{-1}\right)$ agree well for both dives. In addition, there is good agreement in local increases of transflectance along the profile. Differences in both dives result from the fact that not exactly the identical profile was flown, and that sampling along the line was not at the exact same position. Lateral and along-profile shifts affect measured transmittances due to changing ice conditions above the sensor. However, it has to be noted that also the illustrated geometry in Fig. 7a can only represent an interpolated 2-D image of the transect, while also 3-D effects of heterogeneity in snow and ice cover affect the measurements. Comparing the 

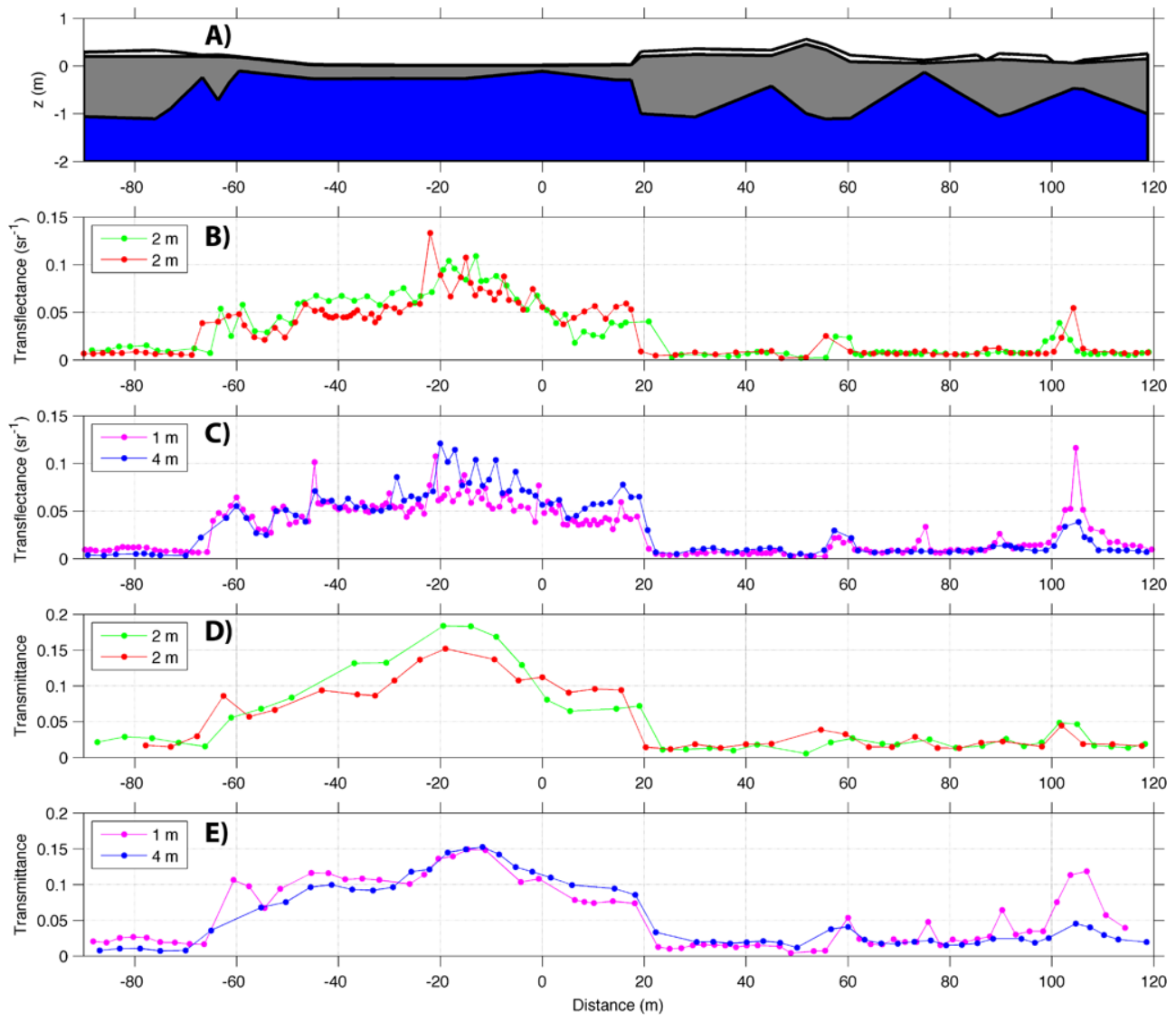

Fig. 7. PAR transflectance and transmittance corrected to ice/water interface at different depths along a profile of snow-covered FYI and a refrozen lead (at $-65<\times<20 \mathrm{~m}$ ) on 9 September 2011. (a) Profile geometry of snow depth, freeboard, and sea-ice draft from drillings. (b, c) Transflectance measured during 2 dives in a depth of $2 \mathrm{~m}$ and at 1.0 and $4.0 \mathrm{~m}$ depth. (d, e) Transmittance measured during the same dives as in (b) and (c). X-axis nomenclature is according to the field settings with the access hole at $x=0 \mathrm{~m}$ (Fig. 2b). Note the different $\mathrm{y}$-axis scale in (d).

transflectance results from Fig. $7 \mathrm{~b}$ and c with those of transmittance in Fig. $7 \mathrm{~d}$ and e shows that the transmittance profile does resolve much more variability along the profile, while the cosine receptor of the transmission measurements results in a much smoother profile with less details. It may also be noted that both data sets do not match in total fluxes due to the different fields of view and related issues of light-field properties.

All dives at 1.0,2.0, and $4.0 \mathrm{~m}$ depths show the same transflectances (Fig. 7b and c) and transmittances (Fig. 7d and e) in both, shape and magnitude. This illustrates that the applied depth correction works well, at least for these uppermost $4.0 \mathrm{~m}$ of the water column and when a close-by depthprofile can be used to derive the necessary extinction coefficients. As expected, the dive at $1.0 \mathrm{~m}$, almost directly at the sea-ice bottom, represents sea-ice and snow geometry in highest detail. In contrast, variability in snow and ice cover is weaker in $4.0 \mathrm{~m}$ depth. At this depth the measured flux results from a much larger surface area due to a larger sensor footprint. Comparing the 1.0 and $4.0 \mathrm{~m}$ dives illustrates the need for measurements close to the ice to resolve smallscale variability. In the $4.0 \mathrm{~m}$ dive, most geometric features of the FYI, as well as variability in the new ice, are strongly dampened, if visible at all. This becomes most obvious for the transmittance profiles where the increasing depth and the hemispheric field of view add up. During data processing, it was also found that deeper transects were more difficult to correlate to surface properties because the positioning error was larger due to different view angles, impacting the passing times of the under-ice markers.

\section{Discussion}

\subsection{Methodological advancements}

Under-ice radiation measurements with ROVs make use of advancements in sensor and ROV technologies. This allows comprehensive studies that were not possible until a few years ago. Using a ROV, it was possible to access the difficult and highly heterogeneous under-ice environment and 
to map radiation through combined horizontal and vertical transects in a few hours at floe-scales (up to $300 \mathrm{~m}$ ). An even larger areal coverage is possible by using longer tether cables or repositioning the access hole on the same ice floe. However, tether length becomes most likely restricted (e.g. around $500 \mathrm{~m}$ ) by practical issues. It adds more and more weight (heavy trim of the tether) to be dragged by the ROV and increases the risk of getting caught under the ice. Another option is to operate the ROV directly from the vessel, as it might be most useful in marginal ice zones or under thin and new sea ice. However, only operating it from ice floes, which were accessible for additional measurements, allowed the acquisition of complementary data sets of sea-ice and snow properties. Beyond the spatial variability on floe scales, the application of these measurements on an ice breaker during a transpolar expedition also allows researchers to obtain large-scale data sets that may be used to compare different sea-ice regimes and regions in the Arctic (Nicolaus et al., 2012a).

The resulting multi-sensor data set of several thousand spectra with coincident sea-ice and snow observations also allows for new approaches in terms of data analyses, such as the use of frequency distributions of radiation data, in order to derive representative modes for different ice conditions and to describe horizontal and vertical variability. Such distributions are more valuable for model and satellite data validation than spot measurements. A first approach that has used modal transmittances by Nicolaus et al. (2012a) showed characteristic differences in light transmission through ponded and white FYI and MYI. But this study was also restricted to Arctic summer, the only time when such data are available. However, this first study underlines the value of such comprehensive data sets to improve our understanding of radiation transfer through the heterogeneous sea ice. In this respect, the large number of observations may also be used to derive a measure of uncertainty and variability for previous (point) measurements (e.g. Light et al., 2008; Nicolaus et al., 2010a), e.g. including additional information on sea-ice and snow conditions. Publishing the presented data set online (doi:10.1594/PANGAEA.786717) also makes the data immediately available for further analyses and comparisons with other observations, model results, and assumptions.

The presented method is almost non-destructive. In future applications, this will also allow repeated transects during different seasons/ice conditions. This is of particular interest, since the understanding of under-ice radiation is still rather poor and only few data exist, combining time series with aspects of spatial variability. Another aspect of the presented approach is that it reduces the need for frequent drillings into the ice, minimizing effects on sea-ice hydrography like artificial surface drainage during spring and summer (Eicken et al., 2004; Polashenski et al., 2012).

\subsection{Multi-sensor approach}

Synchronous measurements of spectral radiance and irradiance are also strongly recommended for upcoming similar studies. Operating two sensors instead of one does not add much effort, complexity, or costs to the measurements, and turns out to be complementary and useful. Due to their different field of view, radiance (and transflectance) results may be well used to describe the spatial variability of under-ice light conditions, while irradiance (and transmittance) measurements are suited to describe the total amount of available short-wave energy beneath sea ice. Especially the radiance measurements resulted in well-defined modal distributions of radiation under sea ice that may be assigned to different surface types and ice conditions. Under-ice radiance and irradiance measurements will contribute to improve our understanding of radiation transfer through sea ice. However, in order to generalize the findings with respect to energy budgets, additional measurements of short- and long-wave fluxes at the ice surface and turbulent fluxes above and under the ice need to be included. Radiation fluxes into the upper ocean through open water can be estimated from the presented ROV measurements in open leads.

Besides the optical data, measurements of sea-ice draft are valuable since transects of sea-ice draft are still sparse. In connection with the radiation measurements, sea-ice thickness is highly important, since it may be expected that new correlations between ice thickness and transmitted radiation could contribute to a better understanding of the energy and light budget of the upper ocean. Here we combined the measurements from the altimeter on the ROV with drillings and EM31 data. This was found to be useful in order to derive sea-ice thickness along the profiles and compare the obtained ice-thickness distribution to large scale airborne and floe scale EM data. Future applications could include additional sensors on the ROV in order to relate those to the optical measurements. In particular, CTD, fluorescence, oxygen, and/or nutrient measurements could help in the study of the connections of physical and biological processes in and under sea ice.

\subsection{Uncertainties}

The greatest uncertainty in the data set was found to be the horizontal positioning, since most positions had to be interpolated between the under-ice markers. However, due to the large amount of data and statistical methods, it may be assumed that this positioning error does not affect the general conclusions, but it has to be taken into account for the interpretation of single measurements and comparisons, as illustrated in Fig. 7. These effects will mostly average out when comparing entire stations or averaging over different sea-ice properties. The use of an under water (under ice) positioning system, e.g. Ultra Short Base Line (USBL), would certainly reduce the time-consuming work to mark transects 
and be more efficient in data post-processing. Furthermore, this would give more freedom in transect planning and allow more flexibility in measurements, though surface properties must still be acquired manually along the profiles. In addition, it would most likely increase the accuracy of positioning, although we are not aware what the accuracy under ice will be and how pressure ridges would affect the positioning since the transponders require a straight line of sight.

Additional sensor intercomparisons showed deviations in PAR fluxes between single radiometers of up to $5 \%$. These differences were corrected during data processing by scaling the spectra with a constant factor over all wavelengths, and also for the depth correction. However, only PAR transmittances and reflectances are discussed here.

Another source of uncertainty is related to data processing. In order to remove the effect of the water between the ice to obtain transmittance through sea ice only, and to quantify and later parameterize fluxes into the ocean, all measurements had to be corrected to the ice/water interface. As a consequence, quantities corrected to the ice water interface combine uncertainties from different sensors, which is particularly difficult for rough ice. At the same time, this correction was found to be significantly more important than a potential correction for sensor inclinations below $10^{\circ}$. Figure 7 shows that the application of the exponential fit to derive extinction coefficients worked sufficiently well. Alternatively, more specific radiative transfer modeling can be used to derive water extinction, but this introduces additional uncertainties, too, e.g. by uncertain input data and insufficient knowledge of the under-ice topography. If payload capacity allows, the use of a spectral transmissometer (e.g. VIPERVIS-Photometer, Trios GmbH, Rastede, Germany) carried on board the ROV could help to obtain in situ water extinction characteristics.

\subsection{Transfer to other studies}

Here we present and discuss the application and results from Arctic summer sea ice only. But the same method, instrumentation, and observation strategy can be used in other seasons and sea ice regions in a very similar way. Depending on ice conditions, the main difference would be the under-ice access, which would demand man-made holes if no melt ponds are present. For thin or new ice, as well as in marginal ice zones and broken ice, the ROV can also be launched and operated from the vessel. With harsher conditions, the operation of the ROV and the work for all complementary measurements will most likely be more time consuming. Depending on weather conditions (mostly temperature) a more solid and better-heated control stand would be needed. Under low solar surface irradiances, as during low-light seasons or around the daily solar minimum, the light conditions under sea ice have to be considered for station planning in order to receive high quality data (signal-noise ratios). Here we only present summer data with wide spread melt-pond coverage and almost no snow cover. This means that transmission is larger than during all other seasons and under-ice fluxes are also among the highest (Nicolaus et al., 2010a). As a consequence, measured under-ice fluxes were large enough to gather high quality data and integration times were not too long. Only on 11 September, when the measurements had to be performed during very low solar elevation angles, the sensor threshold of about $0.1 \mathrm{~W} \mathrm{~m}^{-2}$ was often not reached under sea ice, therefore only few data could be used. Transferring this to surface irradiances, some 10 to $30 \mathrm{~W} \mathrm{~m}^{-2}$ are necessary to perform such under-ice measurements with Ramses radiometers. However, this value would significantly increase with decreasing transmittance, e.g. through snow covers or thicker sea ice.

When transferring these data to other studies, it has to be considered that all presented observations were restricted to the wavelength range from 320 to $950 \mathrm{~nm}$, representing about $80 \%$ of short-wave radiation $(250-2500 \mathrm{~nm})$. Since transmittances above $950 \mathrm{~nm}$ are negligible and those below $350 \mathrm{~nm}$ are also comparably small, this means that presented transflectances and transmittances are larger than for integrals over the short-wave range. Values for the complete shortwave range can be obtained by scaling the presented data set, using reference spectra (e.g. Grenfell and Perovich, 1984).

The example of repeated dives at different depths down to $4.0 \mathrm{~m}$ demonstrates the information loss with increasing depth. This can be compensated to a certain degree with a more narrow field of view (radiance sensors) and higher measurement frequency (if technically possible), but this cannot compensate for the effect of 3-D light scattering in the water. This has to be considered when planning such measurements from AUVs in order to get even larger spatial coverage and wider spread data. In addition, a larger distance to the ice increases the need for high-quality corrections of the signal towards the ice/water interface. This is, as discussed above, one of the greatest uncertainties in this data set.

Besides physical studies and general energy-budget estimates, biological applications could make use of this kind of under-ice light measurement system in order to obtain total amount of biomass in and under sea ice. These studies would be based on the spectral information from the data set with the aim of deriving patterns that can be correlated, e.g. to Chlorophyll $a$ (Chl $a$ ) content (Mundy et al., 2007), a proxy for biomass. So far, gathering these data is highly labor intensive and time consuming. In addition, these methods are usually limited to spot measurements or vertical profiles from water samples.

\section{Conclusions}

The operation of two spectral radiometers on a ROV was found to be highly efficient to map light conditions under sea ice. The ROV was launched through the sea ice and operated 
directly from the ice. This allows direct relations of optical properties to other sea-ice and surface features. The ROV was flown close to the sea ice in order to capture small-scale variability. It is also shown how the ability to resolve spatial variability decreases with increasing distance to the ice. Based on this combination of ROV operations and spectral radiation measurements, it was possible to gather a comprehensive and first-of-its-kind data set (several thousand spectra with an average resolution of $1.0 \mathrm{~m}$ ) of radiation fluxes through Arctic sea ice in summer. The synchronous use of spectral radiance and irradiance sensors turned out to be very beneficial, because this combines conclusions on spatial variability and energy-budget estimates. Both together will enable more detailed studies of light conditions under heterogeneous seaice covers and contribute to a better quantification of light conditions under sea ice. Further combination of these optical measurements with coincident measurements of surface and ice properties can contribute to improve current parameterizations of light transmission through sea ice in numerical models. This would then contribute to our understanding of the large-scale energy-budget of ice-covered oceans.

Acknowledgements. We strongly acknowledge the support of the captain, the crew, and the scientific cruise leader Ursula Schauer of R/V Polarstern cruise ARK-XXVI/3, facilitating the presented measurements. Stefan Hendricks, Mario Hoppmann, Priska Hunkeler, and Robert Ricker contributed significantly to accomplishing the field measurements. We are most grateful to Werner Dimmler for his technical support on Polarstern, as well as the technical support by Ocean Modules, Sweden. Four anonymous reviewers helped with their comments to improve this manuscript. This study was funded through the Alfred-Wegener-Institut, Helmholtz-Zentrum für Polar- und Meeresforschung.

Edited by: R. Lindsay

\section{References}

Arrigo, K. R., Perovich, D. K., Pickart, R. S., Brown, Z. W., van Dijken, G. L., Lowry, K. E., Mills, M. M., Palmer, M. A., Balch, W. M., Bahr, F., Bates, N. R., Benitez-Nelson, C., Bowler, B., Brownlee, E., Ehn, J. K., Frey, K. E., Garley, R., Laney, S. R., Lubelczyk, L., Mathis, J., Matsuoka, A., Mitchell, B. G., Moore, G. W. K., Ortega-Retuerta, E., Pal, S., Polashenski, C. M., Reynolds, R. A., Schieber, B., Sosik, H. M., Stephens, M., and Swift, J. H.: Massive Phytoplankton Blooms Under Arctic Sea Ice, Science, 336, 6087, doi:10.1126/science.1215065, 2012.

Deal, C., Jin, M. B., Elliott, S., Hunke, E., Maltrud, M., and Jeffery, N.: Large-scale modeling of primary production and ice algal biomass within arctic sea ice in 1992, J. Geophys. Res.-Oceans, 116, C07004, doi:10.1029/2010jc006409, 2011.

Ehn, J. K., Mundy, C. J., Barber, D. G., Hop, H., Rossnagel, A., and Stewart, J.: Impact of horizontal spreading on light propagation in melt pond covered seasonal sea ice in the Canadian Arctic, J. Geophys. Res.-Oceans, 116, C00G02, doi:10.1029/2010jc006908, 2011.
Eicken, H., Grenfell, T. C., Perovich, D. K., Richter-Menge, J. A., and Frey, K.: Hydraulic controls of summer Arctic pack ice albedo, J. Geophys. Res., 109, C08007, doi:10.1029/2003JC001989, 2004.

Ficek, D., Kaczmarek, S., Ston-Egiert, J., Wozniak, B., Majchrowski, R., and Dera, J.: Spectra of light absorption by phytoplankton pigments in the Baltic; conclusions to be drawn from a Gaussian analysis of empirical data, Oceanologia, 46, 533-555, 2004.

Frey, K. E., Perovich, D. K., and Light, B.: The spatial distribution of solar radiation under a melting Arctic sea ice cover, Geophys. Res. Lett., 38, L22501, doi:10.1029/2011g1049421, 2011.

Grenfell, T. C.: A Radiative Transfer Model for Sea Ice With Vertical Structure Variations, J. Geophys. Res., 96, 16991-17001, 1991.

Grenfell, T. C. and Perovich, D. K.: Spectral albedos of sea ice and incident solar irradiance in the southern Beaufort Sea, J. Geophys. Res., 89, 3573-3580, 1984.

Grenfell, T. C., Light, B., and Perovich, D. K.: Spectral transmission and implications for the partitioning of shortwave radiation in arctic sea ice, Ann. Glaciol., 44, 1-6, 2006.

Light, B., Grenfell, T. C., and Perovich, D. K.: Transmission and absorption of solar radiation by Arctic sea ice during the melt season, J. Geophys. Res., 113, C03023, doi:10.1029/2006JC003977, 2008.

Mundy, C. J., Barber, D. G., and Michel, C.: Variability of snow and ice thermal, physical and optical properties pertinent to sea ice algae biomass during spring, J. Marine Syst., 58, 107-120, 2005.

Mundy, C. J., Ehn, J. K., Barber, D. G., and Michel, C.: Influence of snow cover and algae on the spectral dependence of transmitted irradiance through Arctic landfast first-year sea ice, J. Geophys. Res., 112, C03007, doi:10.1029/2006JC003683, 2007.

Nicolaus, M., Gerland, S., Hudson, S. R., Hanson, S., Haapala, J., and Perovich, D. K.: Seasonality of spectral albedo and transmissivity as observed in the Arctic Transpolar Drift in 2007, J. Geophys. Res., 115, C11011, doi:10.1029/2009JC006074, 2010a.

Nicolaus, M., Hudson, S. R., Gerland, S., and Munderloh, K.: A modern concept for autonomous and continuous measurements of spectral albedo and transmittance of sea ice, Cold Regions Sci. Technol., 62, 14-28, doi:10.1016/j.coldregions.2010.03.001, 2010b.

Nicolaus, M., Katlein, C., Maslanik, J., and Hendricks, S. Changes in Arctic sea ice result in increasing light transmittance and absorption, Geophys. Res. Lett., 39, L24501, doi:10.1029/2012GL053738, 2012a.

Nicolaus, M., Petrich, C., Hudson, S. R., and Granskog, M. A.: Variability of light transmission through Arctic land-fast sea ice during spring, The Cryosphere Discuss., 6, 4363-4385, doi:10.5194/tcd-6-4363-2012, 2012b.

Perovich, D. K.: Theoretical Estimates of Light Reflection and Transmission by Spatially Complex and Temporally Varying Sea Ice Covers, J. Geophys. Res.-Oceans, 95, 9557-9567, 1990.

Perovich, D. K.: The Optical Properties of Sea Ice, Cold Regions Research and Engeneering Laboratory Monograph, 96-1, 1996.

Perovich, D. K.: On the aggregate-scale partitioning of solar radiation in Arctic sea ice during the Surface Heat Budget of the Arctic Ocean (SHEBA) field experiment, J. Geophys. Res., 110, C03002, doi:10.1029/2004JC002512, 2005. 
Perovich, D. K., Cota, G. F., Maykut, G. A., and Grenfell, T. C.: Bio-optical Observations of First-Year Arctic Sea Ice, Geophys. Res. Lett., 20, 1059-1062, 1993.

Perovich, D. K., Roesler, C. S., and Pegau, W. S.: Variability in Arctic sea ice optical properties, J. Geophys. Res.-Oceans, 103, 1193-1208, 1998.

Petrich, C., Nicolaus, M., and Gradinger, R.: Sensitivity of the light field under sea ice to spatially inhomogeneous optical properties and incident light assessed with three-dimensional Monte Carlo radiative transfer simulations, Cold Regions Sci. Technol., 73, 1-11, doi:10.1016/j.coldregions.2011.12.004, 2012.

Polashenski, C., Perovich, D., and Courville, Z.: The mechanisms of sea ice melt pond formation and evolution, J. Geophys. Res.Oceans, 117, C01001, doi:10.1029/2011jc007231, 2012.
Popova, E. E., Yool, A., Coward, A. C., Dupont, F., Deal, C., Elliott, S., Hunke, E., Jin, M. B., Steele, M., and Zhang, J. L.: What controls primary production in the Arctic Ocean? Results from an intercomparison of five general circulation models with biogeochemistry, J. Geophys. Res.-Oceans, 117, C00D12, doi:10.1029/2011jc007112, 2012.

Roulet, R. R., Maykut, G. A., and Grenfell, I. C.: Spectrophotometers for measurement of light in polar ice and snow, Appl.Optics, 13, 1652-1659, doi:10.1364/ao.13.001652, 1974.

Sturm, M. and Massom, R. A.: Snow and sea ice, in: Sea ice, 2nd Edn., edited by: Thomas, D. N., and Dieckmann, G. S., WileyBlackwell, Chichester, 153-204, 2009.

Warren, S. G., Rigor, I. G., Untersteiner, N., Radionov, V. F., Bryazgin, N. N., Aleksandrov, Y. I., and Colony, R.: Snow depth on Arctic sea ice, J. Climate, 12, 1814-1829, 1999. 